\title{
Mortality-Related Risk Factors in Patients with Pulmonary Arterial Hypertension and Chronic Thromboembolic Pulmonary Hypertension. The Importance of Response to Treatment
}

\author{
Manuel Lopez-Meseguer ${ }^{1,2}$, Río Aguilar ${ }^{3,4}$, Carles Bravo ${ }^{1,2}$, Víctor Monforte $^{1,2}$, Laura Dos ${ }^{5}$, \\ Carmen P. Simeon ${ }^{6}$, Enric Domingo ${ }^{4,5}$, Antonio Roman ${ }^{1,2 \#}$ \\ ${ }^{1}$ Respiratory Department Hospital Universitari Vall d'Hebron, Institut de Recerca del Hospital Universitari Vall d'Hebron, \\ Universitat Autònoma de Barcelona, Barcelona, Spain \\ ${ }^{2}$ Ciber Enfermedades Respiratorias, Instituto de Salud Carlos III, Madrid, Spain \\ ${ }^{3}$ Cardiology Department, Hospital Universitari de Bellvitge, Hospitalet de Llobregat, Spain \\ ${ }^{4}$ Department of Physiology, Universitat Autonòma de Barcelona, Barcelona, Spain \\ ${ }^{5}$ Cardiology Department, Hospital Universitari Vall d'Hebron, Institut de Recerca del Hospital Universitari Vall d'Hebron, Universitat \\ Autònoma de Barcelona, Barcelona, Spain \\ ${ }^{6}$ Internal Medicine Department, Hospital Universitari Vall d’Hebron, Institut de Recerca del Hospital Universitari \\ Vall d'Hebron, Universitat Autònoma de Barcelona, Barcelona, Spain \\ Email: \{manuelop, cbravo, vmonfort, ldos, cpsimeon, enrdomingo, \#aroman\}@vhebron.net, \\ rioaguilar@pulso.com
}

Received January 17, 2012; revised February 10, 2012; accepted February 22, 2012

\begin{abstract}
Background: Pulmonary arterial hypertension (PAH) and chronic thromboembolic pulmonary hypertension (CTEPH) are serious diseases with similar pathophysiologic aspects. The prognosis of patients with these conditions is highly uncertain, particularly incident cases. Methods: A Cox proportional hazards model was applied to a group of 85 patients (81\% women, mean age 52 (18 - 82) years) with PAH (80\%) and non-surgical CTEPH (20\%) to evaluate risk factors for mortality. The following variables were included in the model: age, etiology, baseline 6-minute walk test (6 $\mathrm{mWT}$ ), cardiac index, and improvement in the $6 \mathrm{mWT}$ following initiation of first medical treatment. Results: In the multivariate analysis, the response to treatment, assessed by an improvement on the $6 \mathrm{mWT}$, was the most relevant prognostic factor in these patients (RR, $4.832(95 \% \mathrm{CI}, 1.888-12.364) ; \mathrm{p}=0.001)$. The remaining variables studied in this model had less influence on the prognosis: age > 50 years (RR, 0.744 (95\% CI, $0.26-2.133$ ); p $=0.582$ ); etiology of connective tissue disease-associated PAH (RR, 3.145 (95\% CI, 0.995 - 9.946); p = 0.051) or CTEPH (RR, 0.654 (95\% CI, 0.179 - 2.387); $\mathrm{p}=0.521$ ) with respect to idiopathic PAH; baseline $6 \mathrm{mWT}$ (RR, 1.173 (95\% CI, 0.599 4.895); $\mathrm{p}=0.315$ ); or cardiac index (RR, 2.295 (95\% CI, 0.793 - 6.642); $\mathrm{p}=0.125)$. Conclusions: There is a high degree of uncertainty regarding the prognosis of $\mathrm{PAH}$ and CTEPH at the start of appropriate treatment. Our results support the idea that the initial treatment response is of paramount importance as prognostic factor in these patients.
\end{abstract}

Keywords: Pulmonary Arterial Hypertension; Chronic Thromboembolic Pulmonary Hypertension; Survival; Risk Factors

\section{Introduction}

The incidence of pulmonary arterial hypertension (PAH) is estimated to be 1.1 cases per million [1], and its natural evolution leads to death at an average of 3 years from the time of the diagnosis [2]. The incidence of chronic thromboembolic pulmonary hypertension (CTEPH), re-

\footnotetext{
"COI disclosure: None of the authors have any conflicts of interests to disclose relating this study.

"Corresponding author.
}

mains to be defined, but is estimated to be less than 1\% to $4 \%$ of all cases of pulmonary embolism [3-5]. In non operable CTEPH patients, natural course of the disease is similar to that of PAH.

Because of these low incidences, it is difficult to assemble large groups of patients to better study their prognoses. Classically, attempts to establish the prognosis are based on an analysis of the patients' baseline clinical, functional, and hemodynamic features [2,6]. Exercise capacity and cardiac index (CI) are well-recog- 
nized prognostic factors. Nonetheless, the course of each individual patient remains highly uncertain at the time of the diagnosis. There is some evidence that the response to treatment with epoprostenol has an impact on survival $[7,8]$. We hypothesized that the patient's initial response to the first specific treatment prescribed for PAH has an important influence on prognosis. To investigate this idea, a study of risk factors for mortality was carried out in a group of $\mathrm{PAH}$ and CTEPH patients, all of whom received medical treatment for their disease following a similar scheme.

\section{Patients and Methods}

A retrospective study was performed including 85 adult patients, (69 (81\%) women, mean age at onset of symptoms: 52 (18 - 82) years) diagnosed with PAH classified as group I (idiopathic PAH (IPAH) and connective tissue disease-associated PAH (CTD-PAH)) and group IV (CTEPH) according to the latest Pulmonary Hypertension Classification [9], and followed-up in Hospital Universitari Vall d'Hebron between April 1995 and December 2009 (minimum follow-up, 6 months). Fifty (58.8\%) patients had IPAH, 18 (21.2\%) had CTD-PAH (17 scleroderma and 1 mixed connective tissue disease), and 17 (20\%) had inoperable CTEPH treated with specific medical treatment for PAH.

The diagnosis of both PAH and CTEPH was based on hemodynamic criteria: mean resting pulmonary artery pressure higher than $25 \mathrm{mmHg}$ and mean pulmonary capillary pressure lower than $15 \mathrm{mmHg}$ on right heart catheterization [9]. For the survival analysis, the date when catheterization was performed was considered the date of the diagnosis. All patients had received their first specific treatment for PAH in our unit, which enabled us to study their initial treatment response. The present study has the approval of the IRB of our centre (CEIC Hospital Universitari Vall d'Hebron. Approved in the acta \#190; July 29, 2011).

\section{Statistical Analysis}

Mortality risk factors were evaluated through a Cox proportional hazards model designed to assess the predictive capacity for mortality of 4 blocks of clinically differentiated variables that were included in the model in successive steps. An attempt was made to reproduce the true disease history from the time when patients first consulted and their functional capacity and hemodynamic status are determined, up to the time when treatment is started and the patients' response is evaluated. In the first block of the analysis, age and etiology were included as clinical variables. The second incorporated the baseline functional capacity determined with the six-minute walk test $(6 \mathrm{mWT})$. The third added the CI obtained during diagnostic catheterization, and the fourth included the response to the first specific treatment patients received, defined by the improvement on the $6 \mathrm{mWT}$ in the first 6 to 8 weeks following the start of treatment. For the purposes of the study, a positive treatment response was established when there was any increase between the baseline $6 \mathrm{mWT}$ and the first follow up one after starting treatment.

The variables age, distance walked, and CI were categorized into 2 groups, using the medians of the results obtained as the cut-off value; the variable etiology was categorized into 3 groups (IPAH, CTD-PAH, and CTEPH), with IPAH being the reference group (Table 2).

The data analysis was performed with SPSS, 17.0. Descriptive data are presented as the mean and/or standard deviation. The Kaplan-Meier method was used to calculate survival and Cox proportional hazards regression model to analyze risk factors for mortality. Relative risk (RR) is expressed with the corresponding 95\% confidence interval $(95 \% \mathrm{CI})$. Significance was set at $\mathrm{p}<$ 0.05 for all the tests used.

\section{Results}

Of the 85 patients, 69 (81\%) were women, and the mean age was 52 (18 - 82) years. The mean interval from the onset of symptoms to the diagnosis was 20 (median 14) months. Functional and hemodynamic status are shown in Table 1.

Specific PAH treatment was started in 65 incident patients (77\%) and in 20 (23\%) prevalent patients that were diagnosed before 2002, when the first specific drugs for this condition were approved. Seventy-six patients were started on monotherapy: 44 (51.7\%) with an endothelin receptor antagonist, 17 (20\%) with phosphodiesterase-5 inhibitor, 6 (7\%) with epoprostenol, 2 (2.4\%) with inhaled iloprost and 1 (1.2\%) with subcutaneous treprostinil, and 6 (7\%) with a positive vasorreactivity test, with calcium channel blockers. Nine patients with severe disease were initially treated with a combination of inhaled iloprost plus sildenafil or bosentan.

At study end 22 (25.8\%) patients had stopped follow-up for the following reasons: 2 (2.3\%) lung transplant, 3 (3.5\%) had withdrawn from follow-up, 17 (20\%) had died. The mean duration of follow-up was 45.8 (median: 37.5) months (Figure 1).

The analysis of risk factors for mortality is presented in Table 2. In the univariate analysis neither of the elements in the first block had an effect on mortality. Younger patients did not have a lower risk of death (RR, 0.738 (95\% CI, 0.316 - 1.724); p = 0.482), and there were no significant differences in survival according to the etiology: CTD-PAH patients presented an RR of 2.329 (95\% CI, 0.838 - 6.473) and those with CTEPH an 
Table 1. Baseline information.

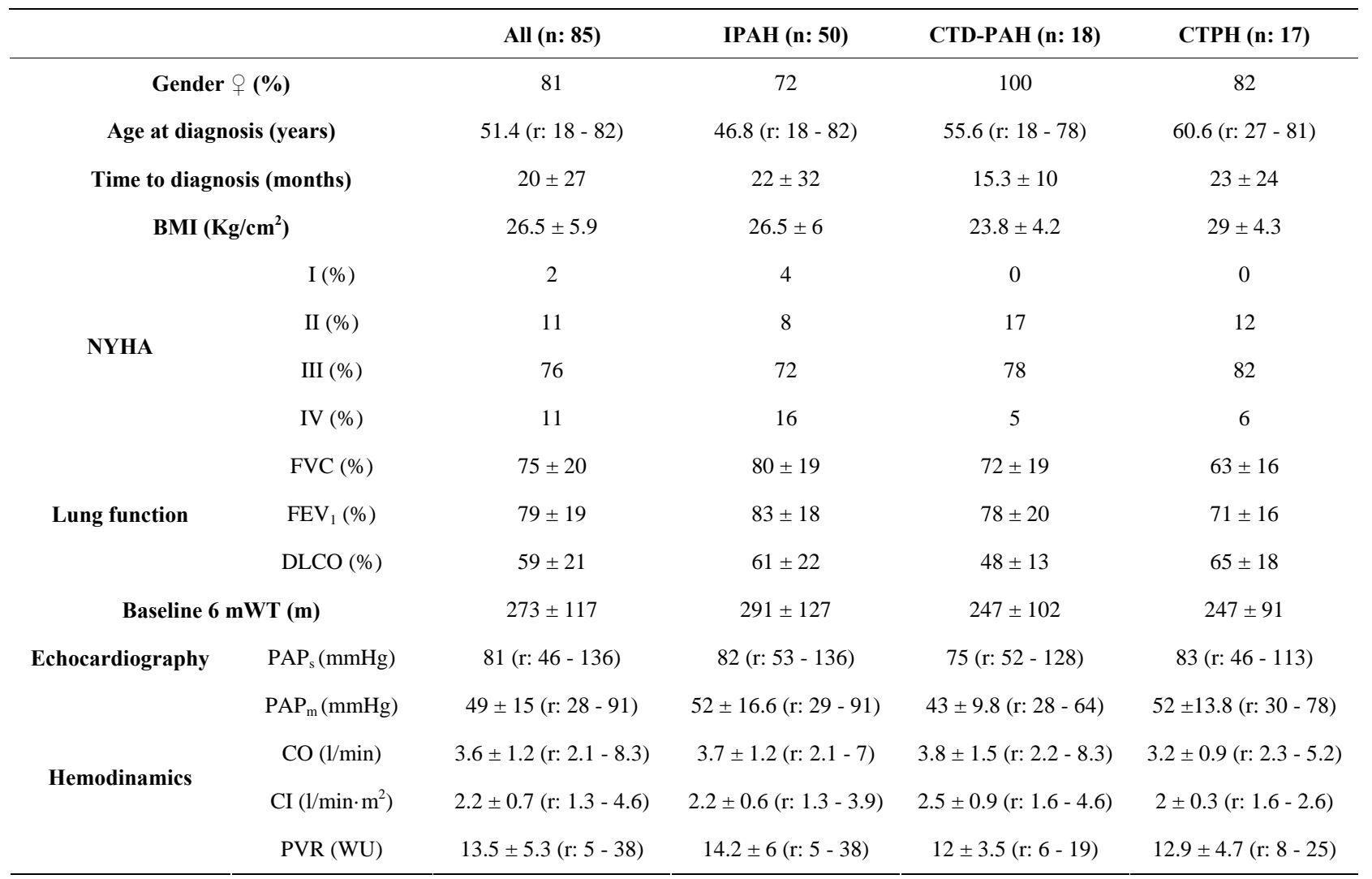

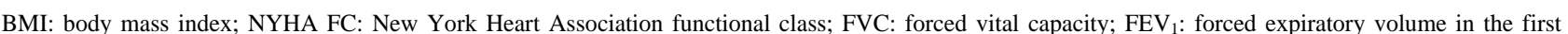
second; DLCO: diffusion lung capacity for carbon monoxide; PAPm: mean pulmonary artery pressure; CO: cardiac output; PVR: pulmonary vascular resistance; WU: wood units.

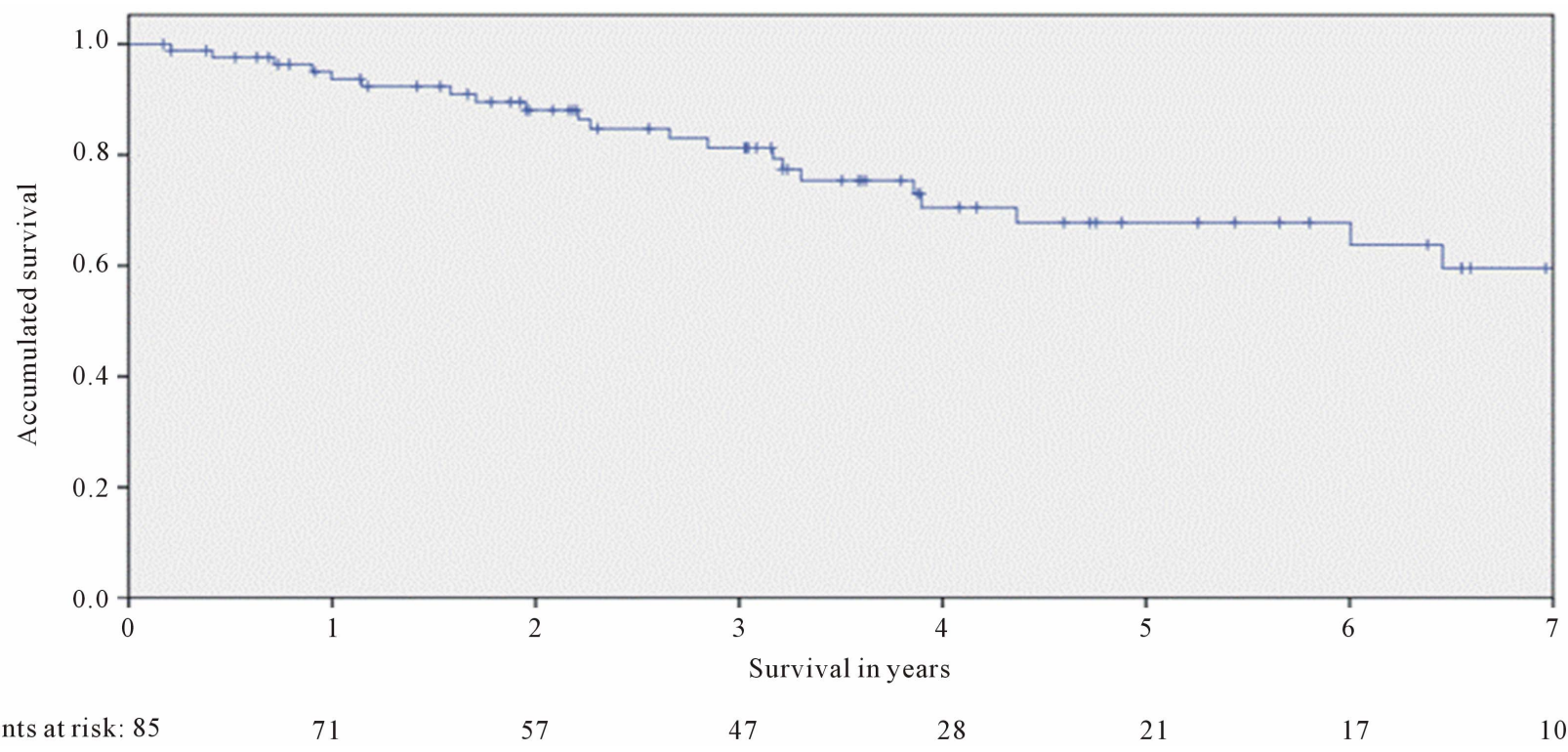

Figure 1. Survival of a group of 85 patients (68 PAH and 17 CTPH).

RR of 1.168 (95\% CI, 0.375 - 3.644), with p values of 0.105 and 0.789 , respectively, relative to those with a diagnosis of IPAH. Univariate analysis of the second block, involving functional capacity at baseline measured by the $6 \mathrm{mWT}$, showed no differences in mortality risk in patients who walked a shorter distance than the median 
Table 2. Cox proportional hazards regression model.

\begin{tabular}{|c|c|c|c|c|c|c|c|c|c|c|c|c|c|c|}
\hline \multicolumn{15}{|c|}{ Cox Proportional Hazards Regression Model } \\
\hline \multirow{3}{*}{ Variables } & \multirow{3}{*}{$\begin{array}{c}\text { Cut-off } \\
\text { (median) }\end{array}$} & \multirow{3}{*}{$\mathbf{n}$} & \multirow{3}{*}{$\begin{array}{c}\text { Death- } \\
\text { transplant }\end{array}$} & \multicolumn{8}{|c|}{ Cumulative probability of survival (Kaplan-Meier) } & \multirow{3}{*}{$\begin{array}{l}\text { Log rank } \\
\text { Breslow } \\
\text { (p) }\end{array}$} & \multirow{3}{*}{$\begin{array}{c}\text { Cross HR } \\
\text { crude } \\
\text { mortality rates } \\
(95 \% \mathrm{CI})\end{array}$} & \multirow{3}{*}{$\begin{array}{l}\text { Cross HR } \\
\text { adjusted mor- } \\
\text { tality rates } \\
(95 \% \mathrm{CI})\end{array}$} \\
\hline & & & & \multicolumn{2}{|c|}{2 years } & \multicolumn{2}{|c|}{4 years } & \multicolumn{2}{|c|}{6 years } & \multicolumn{2}{|c|}{8 years } & & & \\
\hline & & & & $\%$ & SE & $\%$ & SE & $\%$ & SE & $\%$ & SE & & & \\
\hline \multirow{3}{*}{ Age, $y$} & $>50$ & 42 & 11 & 88.1 & 0.057 & 71.4 & 0.089 & 65.5 & 0.099 & 40.9 & 0.153 & \multirow[b]{2}{*}{$\begin{array}{c}\text { LR: } 0.481 \\
\text { B: } 0.869\end{array}$} & 1 & 1 \\
\hline & $<50$ & 43 & 11 & 87.6 & 0.052 & 69.5 & 0.084 & 69.5 & 0.084 & 69.5 & 0.084 & & $\begin{array}{c}0.738 \\
(0.316-1.724) \\
\text { p } 0.482\end{array}$ & $\begin{array}{c}0.744 \\
(0.26-2.133) \\
\text { p } 0.582\end{array}$ \\
\hline & IPAH & 50 & 12 & 91.1 & 0.043 & 72.1 & 0.078 & 72.1 & 0.078 & 66.5 & 0.089 & \multirow{3}{*}{$\begin{array}{c}\text { LR: } 0.243 \\
\text { B: } 0.26\end{array}$} & 1 & 1 \\
\hline \multirow[t]{2}{*}{ Etiology } & CTD-PAH & 18 & 6 & 75.5 & 0.107 & 67.1 & 0.124 & 44.7 & 0.2 & - & - & & $\begin{array}{c}2.329 \\
(0.838-6.473) \\
\text { p } 0.105\end{array}$ & $\begin{array}{c}3.145 \\
(0.995-9.946) \\
\text { p } 0.051\end{array}$ \\
\hline & СТЕРН & 17 & 4 & 93.8 & 0.061 & 74.6 & 0.132 & 74.6 & 0.132 & 49.7 & 0.221 & & $\begin{array}{c}1.168 \\
(0.375-3.644) \\
\text { p } 0.789\end{array}$ & $\begin{array}{c}0.654 \\
(0.179-2.387) \\
\text { p } 0.521\end{array}$ \\
\hline \multirow[b]{2}{*}{$6 \mathrm{mWT}, \mathrm{m}$} & $>288$ & 42 & 12 & 92.4 & 0.042 & 76.5 & 0.082 & 71.4 & 0.091 & 63.4 & 0.11 & \multirow[b]{2}{*}{$\begin{array}{c}\text { LR: } 0.207 \\
\text { B: } 0.063\end{array}$} & 1 & 1 \\
\hline & $<288$ & 43 & 10 & 83.3 & 0.063 & 62.7 & 0.093 & 54.9 & 0.11 & 54.9 & 0.11 & & $\begin{array}{c}1.708 \\
(0.736-3.967) \\
\text { p } 0.213\end{array}$ & $\begin{array}{c}1.173 \\
(0.599-4.895) \\
\text { p } 0.315\end{array}$ \\
\hline \multirow{2}{*}{$\begin{array}{l}\text { Cardiac } \\
\text { index, } \\
\mathrm{L} / \mathrm{min} / \mathrm{m}^{2}\end{array}$} & $>2$ & 42 & 12 & 90.2 & 0.046 & 80.8 & 0.067 & 76.3 & 0.077 & 69.4 & 0.096 & \multirow[b]{2}{*}{$\begin{array}{c}\text { LR: } 0.068 \\
\text { B: } 0.097\end{array}$} & 1 & 1 \\
\hline & $<2$ & 43 & 10 & 86 & 0.059 & 55.6 & 0.109 & 55.6 & 0.109 & 44.5 & 0.132 & & $\begin{array}{c}2.207 \\
(0.924-5.273) \\
\text { p } 0.075\end{array}$ & $\begin{array}{c}2.295(0.793- \\
6.642) \\
\text { p } 0.125\end{array}$ \\
\hline \multirow{2}{*}{$\begin{array}{l}\text { Improvement } \\
6 \text { mWT with } \\
\text { specific } \\
\text { therapy }\end{array}$} & $\mathrm{Si}$ & 51 & 8 & 97.9 & 0.021 & 78.8 & 0.073 & 78.8 & 0.073 & 78.8 & 0.073 & \multirow[b]{2}{*}{$\begin{array}{c}\text { LR: } 0.003 \\
\text { B: } 0.003\end{array}$} & 1 & 1 \\
\hline & No & 34 & 14 & 72.1 & 0.085 & 57 & 0.104 & 49.9 & 0.113 & 29.9 & 0.129 & & $\begin{array}{c}3.438 \\
(1.439-8.214) \\
\text { p } 0.005\end{array}$ & $\begin{array}{c}4.832 \\
(1.888-12.364) \\
\text { p } 0.001\end{array}$ \\
\hline
\end{tabular}

6 mWT: 6-minute walk test; CTD-PAH: connective tissue disease-associated pulmonary artery hypertension; CTEPH: chronic thromboembolic pulmonary hypertension; SE: standard error; HR: hazard ratio; IPAH: idiopathic pulmonary artery hypertension.

(RR, 1.708 (95\% CI, 0.736 - 3.967); p = 0.213). In the third block, containing information on hemodynamic status provided by the CI, patients with an index lower than $2 \mathrm{~L} / \mathrm{min} / \mathrm{m}^{2}$ did not have a significative higher risk of mortality (RR, 2.207 (95\% CI, 0.924 - 5.273); p = 0.075). The last block, which assessed the influence on survival of the treatment response as determined by any increase in the distance covered in the $6 \mathrm{mWT}$, showed that patients did not improve their $6 \mathrm{mWT}$ following the start of specific treatment had a much higher risk of mortality than those who were able to walk a longer distance than at baseline (RR, 3.438 (95\% CI, 1.439 - 8.214); $\mathrm{p}=0.005)$.

In the multivariate analysis, the block 1 variables again showed no effect, with younger patients presenting an RR of 0.744 (95\% CI, $0.26-2.133)(p=0.582)$ and the etiologies as follows: CTD-PAH yielded an RR of 3.145 (95\% CI, 0.995 - 9.946) $(\mathrm{p}=0.051)$ and CTEPH an RR of 0.654 (95\% CI, $0.179-2.387)(\mathrm{p}=0.521)$ with respect to patients with IPAH. Neither the baseline $6 \mathrm{mWT}$ results (RR, 1.173 (95\% CI, 0.599 - 4.895); $\mathrm{p}=0.315)$ nor the CI results (RR, 2.295 (95\% CI, 0.793 - 6.642); $\mathrm{p}=$
0.125) showed prognostic power in the multivariate model. The variable response to treatment, maintained a strong predictive capacity for mortality (RR, 4.832 (95\% $\mathrm{CI}, 1.888$ - 12.364); $\mathrm{p}=0.001$ ) (Figure 2). Among the 51 (60\%) patients who improved their $6 \mathrm{mWT}$ after onset of treatment, the mean increase in the 6-min walk distance was $110 \mathrm{~m}$ from baseline $(259 \pm 123 \mathrm{~m})$ to the first follow up visit (369 $\pm 87 \mathrm{~m})$. The mean increase in the distance walked was greater for patients who were initially in NYHA functional class IV (199 m) than for patients in class III $(26 \mathrm{~m})$, but the absolute distance walked remained lower ( $272 \pm 120 \mathrm{~m}$ vs. $307 \pm 138 \mathrm{~m}$ ). Among the $34(40 \%)$ patients that didn't improve after being treated they experienced a mean decrease in the distance walked of $64 \mathrm{~m}$ from baseline $(293 \pm 106 \mathrm{~m})$ to the first follow up visit (229 $\pm 149 \mathrm{~m})$.

The chi-square value for the incremental predictive capacity of each block of variables based on the log likelihood ratio is shown in Figure 3. At the initial visit, in which only the clinical information is available, represented here by the age and diagnosis, a very high degree of uncertainty is evident $\left(\chi^{2}, 2.94 ; \mathrm{p}=0.401\right)$. There was 


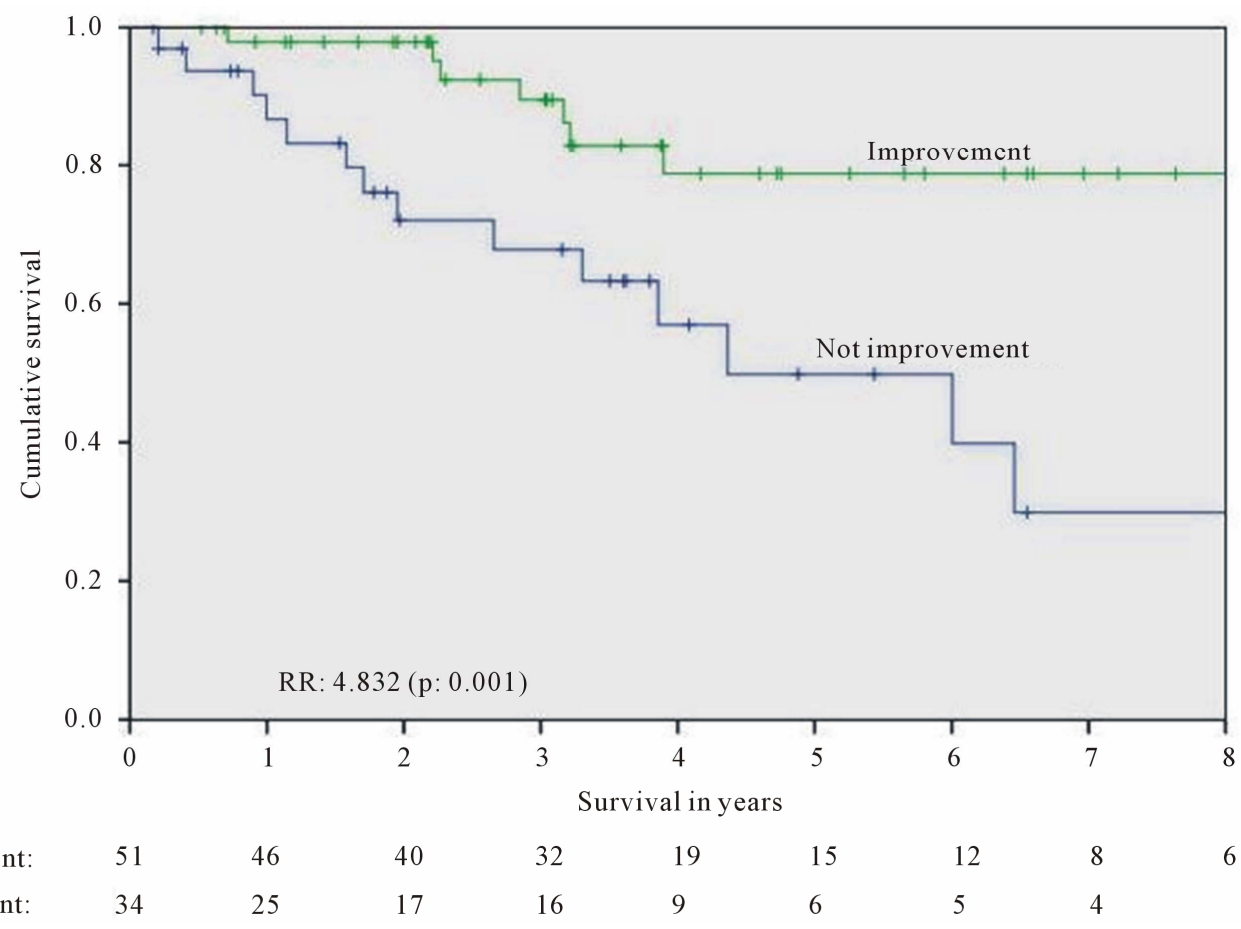

Figure 2. Compared survival in patients with PAH and CTPH according to their response to therapy measured by improvement in $6 \mathrm{mWT}$.

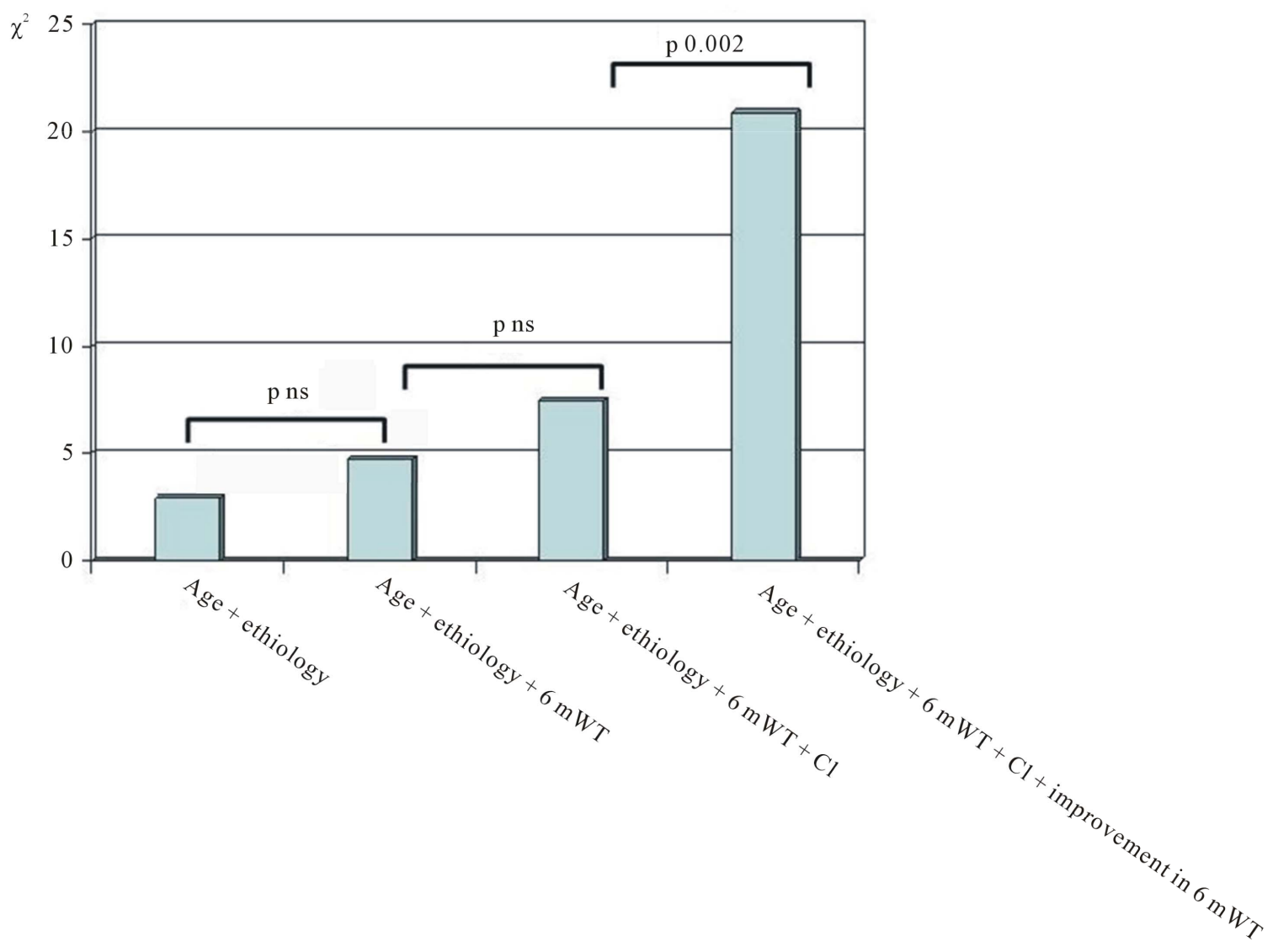

Figure 3. Progressive incremental predictive value of this model. 
only a slight improvement when additional information on the functional status (6 mWT) $\left(\chi^{2}, 4.648 ; \mathrm{p}=0.325\right)$ and hemodynamic status (CI) $\left(\chi^{2}, 7.49 ; \mathrm{p}=0.187\right)$ was provided. The predictive power significantly increased, however, when the last block with information on the disease follow-up and response to treatment was introduced $\left(\chi^{2}, 20.873 ; \mathrm{p}=0.002\right)$.

\section{Discussion}

This study attempts to clarify the factors predictive of the prognosis in PAH and in a subgroup of CTEPH patients who had an indication for medical treatment similar to those with PAH. The model was designed to define the reliability with which the prognosis of PAH can be estimated according to the information available at each phase of the disease management. The most striking finding is the prognostic value of the response to the first specific treatment, measured by an increase in the distance walked in the $6 \mathrm{mWT}$. Patients who showed no improvement in the $6 \mathrm{mWT}$ had an almost 5-fold higher risk of death (RR, 4.8) than those who showed any increase. The development of specific therapies for PAH over the last decade has surely improved the prognosis of patients with this condition [10,11]. Nonetheless, uncertainty regarding the prognosis remains high, and the baseline clinical and hemodynamic parameters do not suffice as reliable predictive factors.

When a patient is seen for the first time and the clinical data are analyzed, the physician may consider that advanced age or a diagnosis of CTD-PAH would indicate a poorer prognosis. It is known the PAH presents a poorer prognosis at both extreme ages of life [12,13]. A poorer prognosis has also been described in CTD-PAH with respect to IPAH $[14,15]$. In our model these factors had no impact on risk, although in the case of CTD-PAH, the RR may have reached significance if the sample size were larger. However, the results obtained allow reasonable speculation that these factors carry less weight for the prognosis than the response to treatment.

Baseline functional status was measured by the distance covered in the $6 \mathrm{mWT}$, as it is a well-recognized prognostic factor in $\mathrm{PAH}$, reported in several articles published in the 1990s $[7,8,16]$. New York Health Association functional class was not analised in order to avoid interferences with distance walked in the Cox model due to the clear and well known correlation of these two parameters. Based on this information, the regulatory agencies have considered changes in the patients' exercise capacity as a surrogate endpoint for survival, and this has enabled clinical development of specific drugs for PAH. The results from clinical trials also confirmed that patients who can walk farther, live longer, and this fact was used to evaluate the optimal response to treatment in clinical practice guidelines. Thus, it has been established that patients able to walk less than $300 \mathrm{~m}$ in the $6 \mathrm{mWT}$ have a poor prognosis, and those able to walk more than $500 \mathrm{~m}$ have a good prognosis [9]. We found no differences in the prognosis related to the baseline $6 \mathrm{mWT}$, possibly because our model contained other factors that were more important.

Other available data at the time of the diagnosis is the baseline hemodynamic study. The CI, one of the measures recorded in this study, was first described to be an important prognostic factor in PAH at the beginning of the 1990s [2] and later studies supported its value [7-9]. The fact that we did not observe differences in survival according to the CI may be due to an insufficient sample size and because of the lower weight of this factor in comparison to the improvement following treatment initiation.

The most relevant result from this study is that the predictive factor with the greatest influence on survival of PAH is the patients' response to the first specific treatment received, established as any improvement in the distance walked in the first $6 \mathrm{mWT}$ performed following treatment initiation. A key related question that currently remains unresolved is what would be the minimum improvement on the $6 \mathrm{mWT}$ that has an impact on survival. In this sense, Sitbon et al. [7] evaluated treatment response as measured by improvements in the NYHA functional class and the $6 \mathrm{mWT}$ in a group of 178 patients diagnosed with IPAH in functional class III or IV, treated with epoprostenol and evaluated at 3 months. The authors reported better survival in patients who walked a greater distance than the group mean $(380 \mathrm{~m})$ in the $6 \mathrm{mWT}$ at 3 months after starting treatment. There were, however, no differences in survival related to the magnitude of the increase in distance walked: patients who improved to a great degree $(>112 \mathrm{~m})$ and those who improved less $(<112 \mathrm{~m})$ presented similar survival. One of the objectives at the start of treatment in these patients is to achieve the greatest possible increase in the distance covered in the $6 \mathrm{mWT}$. Nonetheless, based on the available information, it is not clear that there is a correlation between the magnitude of the improvement and survival; hence, we can assume that any increase in the distance walked has a positive impact on survival. Our results support this concept. Patients who showed no improvement in exercise capacity after starting treatment had a nearly 5 -fold higher risk of mortality on average, than those who did. Our model illustrates how the uncertainty regarding the prognosis of $\mathrm{PAH}$ decreases as additional information about the patient is obtained. However, the initial response to treatment seems to carry a great deal of weight for establishing the prognosis in this patient population.

The decision to include patients from groups I and IV 
of the Pulmonary Hypertension Classification was made for two reasons. First, CTEPH shares certain pathophysiologic characteristics with $\mathrm{PAH}$ in terms of pulmonary vasculature remodeling, which is known to occur even in patients who show macroscopic resolution of the clot [17]. Furthermore, some patients with CTEPH in whom endarterectomy is not indicated respond to specific PAH therapy, an alternative treatment for CTEPH that has been tested in clinical trials $[18,19]$. Lastly, according to our data, survival in CTEPH is similar to that in PAH.

The main limitations of this study are its retrospective nature, a relatively small sample size, and the fact that it was carried out in a single center. Furthermore, we cannot know whether other variables related to treatment response such as hemodynamic parameters or biomarkers are also relevant to the prognosis. Validation of this model of risk predictors in a larger sample would be advisable. Future prospective studies particularly multicenter studies, in which substantial patient groups can be assembled, will be important to determine the value of these results.

In conclusion, the proportional risks model used in this study demonstrated the high degree of uncertainly regarding the prognosis of PAH and CTEPH at the start of medical treatment, and showed that the data related to treatment response are of value in estimating the prognosis of the disease.

\section{REFERENCES}

[1] A. E. Frost, D. B. Badesch, R. J. Barst, R. L. Benza, C. G. Elliott, H. W. Farber, et al., "The Changing Picture of Patients with Pulmonary Arterial Hypertension in the United States: How REVEAL Differs from Historic and Non-US Contemporary Registries,” Chest, Vol. 139, No. 1, 2011, pp. 128-137. doi:10.1378/chest.10-0075

[2] G. E. D’Alonzo, R. J. Barst, S. M. Ayres, E. H. Bergofsky, B. H. Brundage, K. M. Detre, et al., "Survival in Patients with Primary Pulmonary Hypertension: Results from a National Prospective Registry," Annals of Internal Medicine, Vol. 115, No. 5, 1991, pp. 343-349.

[3] V. Pengo, A. W. Lensing, M. H. Prins, A. Marchiori, B. L. Davidson, F. Tiozzo, et al., "Incidence of Chronic Thromboembolic Pulmonary Hypertension after Pulmonary Embolism," The New England Journal of Medicine, Vol. 350, No. 22, 2004, pp. 2257-2264. doi:10.1056/NEJMoa032274

[4] D. Poli, E. Grifoni, E. Antonucci, C. Arcangeli, D. Prisco, R. Abbate, et al., "Incidence of Recurrent Venous Thromboembolism and of Chronic Thromboembolic Pulmonary Hypertension in Patients after a First Episode of Pulmonary Embolism," Journal of Thrombosis Thrombolysis, Vol. 30, No. 3, 2010, pp. 294-299. doi:10.1007/s11239-010-0452-X

[5] C. Becattini, G. Agnelli, R. Pesavento, M. Silingardi, R. Poggio, M. R. Taliani, et al., "Incidence of Chronic Thromboembolic Pulmonary Hypertension after a First Episode of Pulmonary Embolism,” Chest, Vol. 130, No. 1, 2006, pp. 172-175. doi:10.1378/chest.130.1.172

[6] D. B. Badesch, H. C. Champion, M. A. Sanchez, M. M. Hoeper, J. E. Loyd, A. Manes, et al., "Diagnosis and Assessment of Pulmonary Arterial Hypertension,” Journal of the American College of Cardiology, Vol. 54, No. 1, 2009, pp. S55-S66. doi:10.1016/j.jacc.2009.04.011

[7] O. Sitbon, M. Humbert, H. Nunes, F. Parent, G. Garcia, P. Herve, et al., "Long-Term Intravenous Epoprostenol Infusion in Primary Pulmonary Hypertension: Prognostic Factors and Survival," Journal of the American College of Cardiology, Vol. 40, No. 4, 2002, pp. 780-788. doi:10.1016/S0735-1097(02)02012-0

[8] V. V. McLaughlin, A. Shillington and S. Rich. "Clinical Investigation and Reports Survival in Primary Pulmonary Hypertension: The Impact of Epoprostenol Therapy," Circulation, Vol. 106, No. 12, 2002, pp. 1477-1482. doi:10.1161/01.CIR.0000029100.82385.58

[9] N. Galie, M. M. Hoeper, M. Humbert, A. Torbicki, J. L. Vachiery, J. A. Barbera, et al., "Guidelines for the Diagnosis and Treatment of Pulmonary Hypertension,” European Respiratory Journal, Vol. 34, No. 6, 2009, pp. 12191263. doi:10.1183/09031936.00139009

[10] N. Galie, A. Manes, L. Negro, M. Palazzini, M. L. BacchiReggiani and A. Branzi, "A Meta-Analysis of Randomized Controlled Trials in Pulmonary Arterial Hypertension," European Heart Journal, Vol. 30, No. 4, 2009, pp. 394403. doi:10.1093/eurheartj/ehp022

[11] A. Macchia, R. Marchioli, G. Tognoni, M. Scarano, R. Marfisi, L. Tavazzi, et al., "Systematic Review of Trials Using Vasodilators in Pulmonary Arterial Hypertension: Why a New Approach Is Needed," American Heart Journal, Vol. 159, No. 2, 2010, pp. 245-257. doi:10.1016/j.ahj.2009.11.028

[12] V. V. McLaughlin, K. W. Presberg, R. L. Doyle, S. H. Abman, D. C. McCrory, T. Fortin, et al., "Prognosis of Pulmonary Arterial Hypertension: ACCP Evidence-Based Clinical Practice Guidelines,” Chest, Vol. 126, No. 1, 2004, pp. 78S-92S. doi:10.1378/chest.126.1 suppl.78S

[13] S. M. Kawut, D. B. Taichman, C. L. Archer-Chicko, H. I. Palevsky and S. E. Kimmel, "Hemodynamics and Survival in Patients with Pulmonary Arterial Hypertension Related to Systemic Sclerosis," Chest, Vol. 123, No. 2, 2003, pp. 344-350. doi:10.1378/chest.123.2.344

[14] V. McLaughlin, M. Humbert, G. Coghlan, P. Nash and V. Steen, "Pulmonary Arterial Hypertension: The Most Devastating Vascular Complication of Systemic Sclerosis," Rheumatology, Vol. 48, No. 3, 2009, pp. iii25-iii31. doi:10.1093/rheumatology/kep107

[15] S. C. Mathai, L. K. Hummers, H. C. Champion, F. M. Wigley, A. Zaiman, P. M. Hassoun, et al., "Survival in Pulmonary Hypertension Associated with the Scleroderma Spectrum of Diseases: Impact of Interstitial Lung Disease,” Arthritis and Rheumatism, Vol. 60, No. 2, 2009, pp. 569-577. doi:10.1002/art.24267

[16] S. Miyamoto, N. Nagaya, T. Satoh, S. Kyotani, F. Sakamaki, M. Fujita, et al., "Clinical Correlates and Prognostic Significance of Six-Minute Walk Test in Patients with Primary Pulmonary Hypertension: Comparison with Car- 
diopulmonary Exercise Testing," American Journal of Respiratory and Critical Care Medicine, Vol. 161, No. 2, 2000, pp. 487-492.

[17] P. E. Subias, M. J. Cano and A. Flox, "Medical Treatment in Patients with Chronic Thromboembolic Pulmonary Hypertension," Archivos De Bronconeumologia, Vol. 45. No. 6, 2009, pp. 35-39.

[18] X. Jais, A. M. D’Armini, P. Jansa, A. Torbicki, M. Delcroix, H. A. Ghofrani, et al., "Bosentan for Treatment of Inoperable Chronic Thromboembolic Pulmonary Hyper- tension: BENEFiT (Bosentan Effects in iNopErable Forms of ChronIc Thromboembolic Pulmonary Hypertension), a Randomized, Placebo-Controlled Trial," Journal of the American College of Cardiology, Vol. 52, No. 25, 2008, pp. 2127-2134.

[19] H. Olschewski, G. Simonneau, N. Galie, T. Higenbottam, R. Naeije, L. J. Rubin, et al., "Inhaled Iloprost for Severe Pulmonary Hypertension," The New England Journal of Medicine, Vol. 347, No. 5, 2002, pp. 322-329.

doi:10.1056/NEJMoa020204 